2011s-20

\title{
Peer Effects, Fast Food Consumption and Adolescent Weight Gain
}

\author{
Bernard Fortin, Myra Yazbeck
}

\section{Série Scientifique \\ Scientific Series}

\section{Montréal \\ Février 2011}

(C) 2011 Bernard Fortin, Myra Yazbeck. Tous droits réservés. All rights reserved. Reproduction partielle permise avec citation du document source, incluant la notice (C).

Short sections may be quoted without explicit permission, if full credit, including (C) notice, is given to the source.
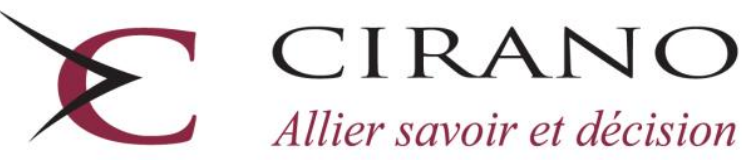

Allier savoir et décision

Centre interuniversitaire de recherche en analyse des organisations 


\section{CIRANO}

Le CIRANO est un organisme sans but lucratif constitué en vertu de la Loi des compagnies du Québec. Le financement de son infrastructure et de ses activités de recherche provient des cotisations de ses organisations-membres, d'une subvention d'infrastructure du Ministère du Développement économique et régional et de la Recherche, de même que des subventions et mandats obtenus par ses équipes de recherche.

CIRANO is a private non-profit organization incorporated under the Québec Companies Act. Its infrastructure and research activities are funded through fees paid by member organizations, an infrastructure grant from the Ministère du Développement économique et régional et de la Recherche, and grants and research mandates obtained by its research teams.

\section{Les partenaires du CIRANO}

Partenaire majeur

Ministère du Développement économique, de l'Innovation et de l'Exportation

\section{Partenaires corporatifs}

Banque de développement du Canada

Banque du Canada

Banque Laurentienne du Canada

Banque Nationale du Canada

Banque Royale du Canada

Banque Scotia

Bell Canada

BMO Groupe financier

Caisse de dépôt et placement du Québec

Fédération des caisses Desjardins du Québec

Financière Sun Life, Québec

Gaz Métro

Hydro-Québec

Industrie Canada

Investissements PSP

Ministère des Finances du Québec

Power Corporation du Canada

Raymond Chabot Grant Thornton

Rio Tinto

State Street Global Advisors

Transat A.T.

Ville de Montréal

\section{Partenaires universitaires}

École Polytechnique de Montréal

HEC Montréal

McGill University

Université Concordia

Université de Montréal

Université de Sherbrooke

Université du Québec

Université du Québec à Montréal

Université Laval

Le CIRANO collabore avec de nombreux centres et chaires de recherche universitaires dont on peut consulter la liste sur son site web.

Les cahiers de la série scientifique (CS) visent à rendre accessibles des résultats de recherche effectuée au CIRANO afin de susciter échanges et commentaires. Ces cahiers sont écrits dans le style des publications scientifiques. Les idées et les opinions émises sont sous l'unique responsabilité des auteurs et ne représentent pas nécessairement les positions du CIRANO ou de ses partenaires.

This paper presents research carried out at CIRANO and aims at encouraging discussion and comment. The observations and viewpoints expressed are the sole responsibility of the authors. They do not necessarily represent positions of CIRANO or its partners. 


\title{
Peer Effects, Fast Food Consumption and Adolescent Weight Gain *
}

\author{
Bernard Fortin ${ }^{\dagger}$, Myra Yazbeck
}

\begin{abstract}
Résumé
Cet article a pour but d'ouvrir la boîte noire des effets de pairs dans les gains de poids chez les adolescents. À partir des données Add Health sur les écoles secondaires aux États-Unis, nous étudions si ces effets découlent en partie des habitudes alimentaires. On suppose que les adolescents interagissent dans le cadre d'un réseau social d'amitié. Nous proposons une analyse des interactions sociales de consommation de malbouffe à l'aide d'un modèle autorégressif spatial généralisé. Nous exploitons les résultats de Bramoullé, Djebbari et Fortin (2009) qui montrent que les liens intransitifs à l'intérieur d'un réseau (i.e., un ami d'un de mes amis n'est pas mon ami) aide à l'identification des effets de pairs. Le modèle est estimé à partir de méthodes de maximum de vraisemblance et de variables instrumentales généralisées. Nous estimons en outre une fonction dynamique de gain de poids reliant l'indice de masse corporelle de l'adolescent (IMC) à sa consommation courante de malbouffe et à son niveau retardée d'IMC. Nos résultats montrent qu'il existe des effets de pairs positifs et significatifs dans la consommation de malbouffe parmi les adolescents appartenant au même réseau d'amis de l'école. Le multiplicateur social est de 1,59. Nos résultats suggèrent de plus qu'au niveau du réseau social, une journée additionnelle de consommation hebdomadaire dans un restaurant de malbouffe augmente l'IMC de 2,4\%, lorsque les effets de pairs sont pris en compte.
\end{abstract}

Mots clés : Obésité, embompoint, effets de pair, malbouffe, réseaux sociaux, modèle autorégressif spatial.

\footnotetext{
* An earlier version of this paper was presented at the Spatial Econometrics Conference (July 2009). We wish to thank Christopher Auld, Charles Bellemare, Luc Bissonnette, Guy Lacroix, Paul Makdissi, and Bruce Shearer, for useful comments and Habiba Djebbari, Yann Bramoullé, Badi Baltagi, Lynda Khalaf and Lung-Fei Lee for useful discussions. All remaining errors are ours. Financial support from the Canada Research Chair in the Economics of Social Policies and Human Resources and le Centre interuniversitaire sur le risque, les politiques économiques et l'emploi is gratefully acknowledged. This research uses data from Add Health, a program project directed by Kathleen Mullan Harris and designed by J. Richard Udry, Peter S. Bearman, and Kathleen Mullan Harris at the University of North Carolina at Chapel Hill, and funded by grant P01-HD31921 from the Eunice Kennedy Shriver National Institute of Child Health and Human Development, with cooperative funding from 23 other federal agencies and foundations.

${ }^{\dagger}$ CIRPÉE, IZA, CIRANO and Department of Economics, Université Laval. E-mail: Bernard.Fortin@ecn.ulaval.ca

${ }^{\ddagger}$ CIRPÉE and Department of Economics, Université Laval. Email: myazbeck@ecn.ulaval.ca
} 


\begin{abstract}
This paper aims at opening the black box of peer effects in adolescent weight gain. Using Add Health data on secondary schools in the U.S., we investigate whether these effects partly flow through the eating habits channel. Adolescents are assumed to interact through a friendship social network. We first propose a social interaction model of fast food consumption using a generalized spatial autoregressive approach. We exploit results by Bramoullé, Djebbari and Fortin (2009) which show that intransitive links within a network (i.e., a friend of one of my friends is not my friend) help identify peer effects. The model is estimated using maximum likelihood and generalized 2SLS strategies. We also estimate a panel dynamic weight gain production function relating an adolescent's Body Mass Index (BMI) to his current fast food consumption and his lagged BMI level. Results show that there are positive significant peer effects in fast food consumption among adolescents belonging to a same friendship school network. The estimated social multiplier is 1.59. Our results also suggest that, at the network level, an extra day of weekly fast food restaurant visits increases BMI by $2.4 \%$, when peer effects are taken into account.
\end{abstract}

Mots clés : Obesity, overweight, peer effects, social interactions, fast food, spatial models.

Keywords: C31, I10, I12 


\section{Introduction}

For the past few years, obesity has been one of the major concerns of health policy makers in the U.S. It has also been one of the principal sources of increased health care costs. In fact, the increasing trend in children's and adolescents' obesity has raised the annual obesity-related hospital costs for this part of the population to $\$ 127$ million per year. Obesity is also associated with increased risk of reduced life expectancy as well as with serious health problems such as type 2 diabetes (Ford et al., 1997; Hu et al., 2001; Maggio and Pi-Sunyer, 2003), heart disease (Li et al., 2006; Calabr et al., 2009) and certain cancers (Abu-Abid et al., 2002; Calle, 2007), making obesity a real public health challenge.

Recently, a growing body of the health economics literature has tried to look into the obesity problem from a new perspective using a social interaction framework. The evidence suggests the presence of strong peer effects in weight gain. Christakis and Fowler (2007), Trogdon et al. (2008) and Renna et al. (2008) seem to be unanimously pointing at the social multiplier as an important element in the obesity epidemics. ${ }^{1}$ A social multiplier may amplify, at the aggregate level, the impact of any shock that affects obesity at the individual level. This is so because the aggregate (per capita) effect incorporates, in addition to the individual direct effect, positive peer effects stemming from social interactions. ${ }^{2}$

While the presence of the social multiplier in weight gain has been widely researched, the literature on the mechanisms by which this multiplier flows is still scarce. Indeed, most of the relevant literature attempts to estimate the relationship between variables such as an individual's Body Mass Index (BMI) and his average peers' BMI, without exploring the channels at source of this potential linkage. ${ }^{3}$ The aim of this paper is to go beyond the black box approach of peer effects in weight gain and try to identify one crucial mechanism through which peer effects in adolescence overweight may flow: eating habits (fast

\footnotetext{
${ }^{1}$ While Cohen-Cole and Fletcher (2008) found that there is no evidence of peer effects in weight gain, most of the literature is consistent with the presence of these effects. Also, see Fowler and Christakis (2008) in reply to Cohen-Cole and Fletcher (2008).

${ }^{2}$ Researchers also found that friends had a significant effect in adolescent smoking, drinking, illicit drug use (Clark and Loheac, 2007) and risky sex (Jaccard et al., 2005).

${ }^{3}$ One recent exception is Yakusheva et al. (2010) who look at peer effects in weight gain and in weight management behaviours such as eating and physical exercise, using randomly assigned pairs of roommates in freshman year.
} 
food consumption). ${ }^{4}$

Three reasons justify our interest in eating habits in analyzing the impact of peer effects on teenage weight gain. First of all, there is important literature that points to eating habits as an important component in weight gain (e.g., Levitsky et al., 2004; Niemeier et al., 2006; Rosenheck, 2008). ${ }^{5}$ Secondly, one suspects that peer effects in eating habits are likely to be important in adolescence. Indeed, at this age, youngsters have increased independence in general and more freedom as far as their food choices are concerned (Rolfes and Whitney, 1996). Usually vulnerable, they often compare themselves to their friends and may alter their choices to conform to the behaviour of their peers. Therefore, unless we scientifically prove that obesity is a virus, ${ }^{6}$ it is counter intuitive to think that one can gain weight by simply interacting with an obese person. This is why we are inclined to think that the presence of real peer effects in weight gain can be estimated using behavioural channels such as eating habits. Thirdly, our interest in peer effects in youths' eating habits is policy driven. There has been much discussion on implementing tax policies to address the problem of obesity (e.g., Jacobson and Brownell, 2000; Marshall, 2000; Kim and Kawachi, 2006; Caraher and Cowburn, 2007). As long as peer effects in fast food consumption is a source of externality that may stimulate overweight among adolescents, it may be justified to introduce a consumption tax on fast food. The optimal level of this tax will depend, among other things, on the social multiplier of eating habits, and on the causal effect of fast food consumption on adolescent weight.

In order to analyze the impact of peer effects in eating habits on weight gain, we propose a two equation model. The first equation relates the teenager's fast food consumption to his reference group's mean fast food consumption (endogenous peer effect), his individual characteristics, and his reference group's

\footnotetext{
${ }^{4}$ Another potentially important channel is physical activity (Trogdon et al., 2008).

${ }^{5} \mathrm{An}$ indirect evidence of the relationship between eating habits and weight gain come from the literature on the (negative) effect of fast food prices on adolescent BMI (see Chou et al., 2005; Powell et al., 2007; Auld and Powell, 2008; Powell and Bao, 2009). See also Cutler et al. (2003) which relates the declining relative price of fast food and the increase in fast food restaurant availability over time to increasing obesity in the U.S.

${ }^{6}$ We acknowledge that some recent studies have pointed that obesity might be partially due to a virus ad-36 (see Rogers et al., 2007).
} 
mean characteristics (contextual peer effects). This linear-in-means equation provides an estimate of the social multiplier effect of eating habits on fast-food consumption. The second equation is a panel dynamic production function that relates the teenager's BMI to his current fast food consumption and his lagged BMI level. The system of equations thus allows us to evaluate the impact of an eating habits' exogenous shock on weight gain, when peer effects on fast food consumption are taken into account.

Estimating our system of equations raises serious econometric problems. It is well known that the identification of peers effects (first equation) is a challenging task. These identification issues were pointed out by Manski (1993) and discussed among others by Moffit (2001), Brock and Durlauf (2001), and Durlauf (2004). On one hand, it is difficult to separate the total (endogenous + contextual) peer effect, often referred to as social effects, from the correlated effects, that is, those coming from the endogeneity of network formation. For instance, correlated effects may result from the fact that individuals from the same network tend to behave similarly because they are alike or share a common environment. On the other hand, simultaneity between an adolescent's behaviour and his peers' behaviour (referred to as the reflection problem by Manski (1993)) makes it difficult to identify separately the endogenous peer effect and the contextual effects. This later task is important since the endogenous peer effect is the only source for a social multiplier.

We use a new approach to address these identification problems and to estimate the peer effects equation. First, we assume that in their fast food consumption decisions, adolescents interact through a friendship network. We deal with the problem of correlated effects by considering those that are attributed to the fact that adolescents share the same environment and/or same preferences. We thus consider these correlated effects as fixed effects at the network level. Moreover, to solve the reflection problem, we exploit results by Bramoullé, Djebbari and Fortin (2009) who show that intransitive triads within a network (i.e., a friend of one of my friends is not my friend) help identify peer effects. The intuition is that this provides exclusion restrictions in the model. Specifically, the friends' friends mean character- 
istics can be used as instruments for the mean friends' fast food consumption. ${ }^{7}$ Finally, we exploit the similarity between the linear-in-means model and the spatial autoregressive (SAR) model. The model is estimated using a maximum likelihood (ML) approach as in Lee et al. (2010) and Lin (2010). We also estimate the model with a distribution free approach: generalized spatial two-stage least square (GS-2SLS) proposed in Kelejian and Prucha (1998) and refined in Lee (2003).

The estimation of the dynamic weight gain production function (second equation) also raises some challenging issues as fast food consumption and past BMI level are likely to be endogenous variables. In order to deal with these problems, we follow Arellano and Bond (1991) by first differencing the equation to eliminate the individual effects and by exploiting the orthogonality conditions that exist between lagged values of BMI and the current disturbances to generate instruments.

To estimate our model, we use three waves of the National Longitudinal Study of Adolescent Health (Add Health). We define peers as the nominated group of individuals reported as friends within the same school. The consumption behaviour is depicted through the reported frequency (in days) of fast food restaurant visits in the past week. Results suggest that there is a positive significant peer effect in fast food consumption among adolescents in general. The estimated social multiplier is 1.59. Moreover, the production function estimates indicate that there is a positive significant impact of fast food consumption on BMI. Combining these results, we find that, at the network level, an extra day of fast food restaurant visits per week increases BMI by $2.4 \%$ on average within a year.

The remaining parts of this paper will be laid out as follows. Section 2 provides a survey of the literature on the impact of fast food consumption on obesity and on the impact of peer effects on fast food consumption. Section 3 presents our two-equation model and our estimation methods. In section 4, we give a brief overview of the Add Health Survey and we provide descriptive statistics of the data

\footnotetext{
${ }^{7}$ This result is strictly correct when there are no fixed effects. When the model includes fixed effects, the peer effects can be recovered if one can find at least two students in the network who are not friends but are linked by two friends (Bramoullé et al., 2009). See section 3.1. for more details.
} 
we use. In section 5, we discuss estimation results. Section 6 concludes.

\section{Survey of the literature}

The general issue addressed in this paper is whether the peer effects in weight gain among adolescents partly flow through the eating habits channel. This raises two more basic issues: a) Are there peer effects in fast food consumption?, and b) Is there a link between weight gain (or obesity) and fast food consumption? In this paper, we address both issues. The literature on peer effects in eating habits (first issue) is recent and quite limited. In a medical experimental context, Salvy et al. (2008) assess the presence of "peer effect" in pre-adolescent girls' snack intake as a function of the co-eaters' weight status. They show that overweight girls eating with an overweight peer consumed more calories than overweight participants eating with normal weight peers. In a recent natural experiment, Yakusheva et al. (2010) estimate peer effects in explaining weight gain among freshman girls using a similar set up but in school dormitories. Also, they test whether some of the student's weight management behaviours (i.e., eating habits, physical exercise, use of weight loss supplements) can be predicted by her randomly assigned roommate's behaviours. Their results provide evidence of the presence of negative peer effects in weight gain. Their results also suggest positive peer effects in eating habits, exercise and use of weight loss supplements.

Two caveats of these two studies are their focus on girls and their limited sample (e.g., recruited participants, freshman level students). Moreover their estimates are likely to underestimate social interactions effects as co-eaters or roommates do not reflect the true social network influencing students' weight management behaviours (Stinebrickner and Stinebrickner, 2006). Finally, these studies do not estimate the causal links between behaviours and weight gain. Our paper finds its basis in this literature as

well as the literature on peer effects and obesity (Christakis and Fowler, 2007; Trogdon et al., 2008; Renna et al., 2008) . However, while both works by Salvy et al. (2008) and Yakusheva et al. (2010) rely upon 
experimental data, we use non-experimental data. Thus, peers are not limited to assigned dyads. Rather, they are considered to have social interactions within a school network. This allows for the construction of a social interaction matrix that reflects how social interaction between adolescents in schools occurs in a more realistic setting (as in Trogdon et al., 2008; Renna et al., 2008). An additional originality of our paper lies in the fact that it relies upon a structural (linear-in-means) approach when relating an adolescent's behaviour to that of his peers. Also, the analogy between the forms of the linear-in-means model and the spatial autoregressive (SAR) model allows us to exploit the particularities of this latter model, namely the natural instruments that are derived from its reduced form.

Regarding the second issue, i.e., the relationship between weight gain (or obesity) and fast food consumption, it is an empirical question that is still on the debate table. ${ }^{8}$ There is no clear evidence in support of a causal link between fast food consumption and obesity. Nevertheless, most of the literature in epidemiology find evidence of a positive correlation between fast food consumption and obesity (see for a survey, Rosenheck, 2008). ${ }^{9}$

The economic literature reveals to be conservative with respect to this question. It focuses the impact of "exposure" to fast food on obesity. Dunn (2008), using an instrumental variable approach, investigates the relationship between fast food availability and obesity. He finds that an increase in the number of fast food restaurants has a positive effect on the BMI. Similarly, Currie et al. (2009) find evidence that proximity to fast food restaurants has a significant effect on obesity for 9th graders. On the other hand, Chen et al. (2009) found a small but statistically significant effect in favour of a relationship between BMI values and the density of fast food restaurants.

The factors underlying fast food consumption were also investigated. Jeffery and French (1998) show that hours of TV viewing per day and the frequency of meals eaten at fast food restaurants are both

\footnotetext{
${ }^{8}$ The literature on the impact of physical activity on obesity is also inconclusive. For instance, Berentzen et al. (2008) provide evidence that decreased physical activity in adults does not lead to obesity.

${ }^{9}$ For instance Bowman et al. (2004) finds that children who consumed fast food consumed more total energy.
} 
positively associated with increase in the BMI of women. One drawback of this study is that it uses a non representative sample (i.e., individuals who volunteered for the study of weight gain prevention). Chou et al. (2005) find a strong positive correlation between exposure to fast food restaurant advertising and the probability that children and adolescents are overweight. This effect seems to be stronger and more significant for girls (Chou et al., 2005). In fact, this influence can be clearly seen as children are more likely to pick up items that are in "Mac Donald's" packaging (Robinson et al., 2007). More generally, Cutler et al. (2003) and Bleich et al. (2008) argue that the increased calorie intake (i.e., eating habits) plays a major role in explaining current obesity rates. Importantly, weight gain prior to adulthood set the stage for weight gain in adulthood.

While most of the economics literature analyses the relationship between adolescents' fast food consumption and their weight gain using an indirect approach (i.e, effect to fast food exposure), we adopt a direct approach in this paper. More precisely, we estimate a dynamic model of weight gain as a function of fast food consumption and lagged weight gain. In order to account for the endogeneity of regressors, we follow instrumental methods that were developed in the econometrics literature to estimate panel dynamic models.

\section{Structural econometric model}

In this section, we first propose a linear-in-means peer effects model of the adolescent's fast food consumption (first equation) and discuss the econometric methods we use to estimate it. We then present

our dynamic weight gain production function which relates the adolescent's BMI level to his fast food consumption (second equation). 


\subsection{A structural model of peer effects in fast food consumption}

Suppose that we have a set of $\mathrm{N}$ adolescents $i$ that are partitioned in a set of $L$ networks. A network is defined as a structure (e.g., school) in which adolescents are potentially tied by a friendship link. Each adolescent $i$ in his network has a set of nominated friends $N_{i}$ of size $n_{i}$ that constitute his reference group (or peers). We assume that $i$ is excluded from his reference group. Since peers are defined as nominated friends, the number of peers will not be the same for every network member. Let $\mathbf{G}_{l}(l=1, \ldots, L)$ be the social interaction matrix for a network $l$. Its element $g_{i j l}$ takes a value of $\frac{1}{n_{i}}$ when $i$ is friend with $j$, and zero otherwise. ${ }^{10}$ We define $y_{i l}$ as the fast food consumed by adolescent $i$ in network $l, x_{i l}$ represents the adolescent $i^{\prime}$ s observable characteristics, $\mathbf{y}_{l}$ the vector of fast food consumption in network $l$, and $\mathbf{x}_{l}$ is the corresponding vector for individual characteristics. To simplify our presentation, we look at only one characteristic (e.g., adolescent pocket money). ${ }^{11}$ The correlated effects are partly captured through network fixed effects (the $\alpha_{l}$ 's). They take into account common unobserved factors such as school snack policies, presence of fast food restaurants around the school, or availability of recreational facilities in school.The $\varepsilon_{i l}$ 's are the idiosyncratic error terms. They capture $i$ 's unobservable characteristics that are not invariant within the network. Formally, one can write the linear-in-means model for adolescent $i$ as follows:

$$
y_{i l}=\alpha_{l}+\beta \frac{\sum_{j \in N_{i}} y_{l j}}{n_{i}}+\gamma x_{l i}+\delta \frac{\sum_{j \in N_{i}} x_{l j}}{n_{i}}+\varepsilon_{l i}
$$

where $\frac{\sum_{j \in N_{i}} y_{l j}}{n_{i}}$ and $\frac{\sum_{j \in N_{i}} x_{l j}}{n_{i}}$ are respectively his peers' mean fast food consumed and characteristics. ${ }^{12}$ In the context of our paper, $\beta$ is the endogenous peer effect. It reflects how the adolescent's consumption of fast food is affected by his peers' mean fast food consumption. It is standard to assume that $|\beta|<1$.

The contextual peer effect is represented by the parameter $\delta$. It captures the impact of his peers' mean

\footnotetext{
${ }^{10}$ Therefore, the $\mathbf{G}_{l}$ matrix is row normalized.

${ }^{11}$ The model can be easily generalized using more than one characteristic.

${ }^{12}$ This structural model can be derived from a choice-theoretic approach where each adolescent's fast food consumption is obtained from the maximization of his quadratic utility function which depends on his individual characteristics, his own fast food consumption and his reference group's mean fast food consumption and mean characteristics. This approach also assumes that social interactions have reached a noncooperative (Nash) equilibrium.
} 
characteristic on his fast food consumption. It is important to note that the matrices of $\mathbf{G}_{l}$ 's and the vectors of $\mathbf{x}_{l}$ 's are stochastic but assumed strictly exogenous conditional on $\alpha_{l}$, that is, $\mathbb{E}\left(\varepsilon_{l i} \mid \mathbf{x}_{l}, \mathbf{G}_{l}, \alpha_{l}\right)=0$. This assumption is flexible enough to allow for correlation between the network's unobserved common characteristics (e.g., school's cafeteria quality) and observed characteristics (e.g., parents' education). ${ }^{13}$ Nevertheless, once we condition on these common characteristics, parents' education is assumed to be independent of $i^{\prime}$ s idiosyncratic unobserved characteristics. Let $\mathbf{I}_{l}$ be the identity matrix for a network $l$ and $\iota_{l}$ the corresponding vector of ones, the structural model (1) for network $l$ can be rewritten in matrix notation as follows:

$$
\mathbf{y}_{l}=\alpha_{l} \iota_{l}+\beta \mathbf{G}_{l} \mathbf{y}_{l}+\gamma \mathbf{x}_{l}+\delta \mathbf{G}_{l} \mathbf{x}_{l}+\varepsilon_{l}, \text { for } l=1, \ldots, L .
$$

Note that model (2) is similar to a SAR model (e.g., Cliff and Ord, 1981) generalized to allow for contextual and fixed effects (hereinafter referred to as the GSAR model). Since $|\beta|<1,\left(\mathbf{I}_{l}-\beta \mathbf{G}_{l}\right)$ is invertible. Therefore, in matrix notation, the reduced form of the model can be written as:

$$
\mathbf{y}_{l}=\alpha_{l} /(1-\beta) \boldsymbol{\iota}_{l}+\left(\mathbf{I}_{l}-\beta \mathbf{G}_{l}\right)^{-1}\left(\gamma \mathbf{I}_{l}+\delta \mathbf{G}_{l}\right) \mathbf{x}_{l}+\left(\mathbf{I}_{l}-\beta \mathbf{G}_{l}\right)^{-1} \varepsilon_{l}
$$

where we use the result that $\left(\mathbf{I}-\beta \mathbf{G}_{l}\right)^{-1}=\sum_{k=0}^{\infty} \beta^{k} \mathbf{G}_{l}^{k}$, so that the vector of intercepts is $\alpha_{l} /(1-\beta) \boldsymbol{\iota}_{l}$, asuming no isolated adolescents. ${ }^{14}$

Equation (3) allows us to evaluate the impact of a marginal shock in $\alpha_{l}$ (i.e., a common exogenous change in fast food consumption within the network) on an adolescent $i$ 's fast food consumption, when the endogenous peer effect is taken into account. One has $\partial y_{i l} / \partial \alpha_{l}=1 /(1-\beta)$. This expression is defined as the social multiplier in our model. When $\beta>0$ (strategic complementarities in fast food consumption), the social multiplier is larger than 1 . In this case, the impact of the shock is amplified by social interactions.

We then perform a panel-like within transformation to the model. More precisely, we average equation (3) over all students in network $l$ and subtract it from $i$ 's equation. This transformation allows us to

\footnotetext{
${ }^{13}$ In this case $\mathbb{E}\left(\alpha_{l} \mid \mathbf{G}_{l}, \mathbf{x}_{l}\right) \neq 0$.

${ }^{14}$ When an adolescent is isolated, that is, with an empty group of friends, his intercept is $\alpha_{l}$.
} 
address problems that arise from the fact adolescents are sharing the same environment or preferences. Let $\mathbf{K}_{l}=\mathbf{I}_{l}-\mathbf{H}_{l}$ be the matrix that obtains the deviation from network $l$ mean with $\mathbf{H}_{l}=\frac{1}{n_{l}}\left(\iota_{l} \iota_{l}^{\prime}\right)$. The network within transformation will eliminate the correlated effect $\alpha_{l}$. Pre-multiplying (3) by $\mathbf{K}_{l}$ yields the reduced form of the model for network $l$, in deviation:

$$
\mathbf{K}_{l} \mathbf{y}_{l}=\mathbf{K}_{l}\left(\mathbf{I}_{l}-\beta \mathbf{G}_{l}\right)^{-1}\left(\gamma \mathbf{I}_{l}+\delta \mathbf{G}_{l}\right) \mathbf{x}_{l}+\mathbf{K}_{l}\left(\mathbf{I}_{l}-\beta \mathbf{G}_{l}\right)^{-1} \varepsilon_{l}
$$

Now let us define $\mathbf{G}$ the block-diagonal matrix with the $\mathbf{G}_{l}$ 's on its diagonal. In the absence of correlated effects (i.e., $\alpha_{l}=\alpha$ for all $l$ ), Bramoullé et al. (2009) show that the structural parameters of the model (2) are identified if the matrices $\mathbf{I}, \mathbf{G}, \mathbf{G}^{2}$ are linearly independent. This condition is satisfied when there is at least one intransitive triad within a network (i.e., a friend's friend of an adolescent is not his friend).The intuition is that this provides exclusion restrictions in the model. More precisely, the friends' friends mean characteristics can served as instruments for the mean friends' fast food consumption. Of course, when correlated effects are allowed, the identification conditions are more restrictive. Bramoullé et al. (2009) show that, in this case, the structural parameters are identified if the matrices $\mathbf{I}, \mathbf{G}, \mathbf{G}^{2}$ and $\mathbf{G}^{3}$ are linearly independent, a condition that will be checked with the data we use. This condition will be satisfied for example when the diameter of a network (i.e., maximal friendship distance) is greater than or equal to $3 .{ }^{15}$ Then, we can find two adolescents who are not friends but are linked by two friends.

Other types of correlated effects can occur for reasons other than common environmental factors. For instance, one can think of other uncommon unobserved reasons for which some people might group together. To account for this possibility we allow for spatial autocorrelation in the error terms so that our model structure becomes analogous to that of a generalized spatial autoregressive model with spatial autoregressive disturbances (hereinafter referred to as the GSARAR model). In this case, the error terms in (2) can be written as:

\footnotetext{
${ }^{15}$ The diameter of the network is defined as the maximal distance that can relate any two adolescents in a network, where the distance is the minimal segment that links any two adolescents.
} 


$$
\varepsilon_{l}=\rho \mathbf{G}_{l} \varepsilon_{l}+\boldsymbol{\xi}_{l}
$$

where the innovations, $\boldsymbol{\xi}_{l}$, are assumed to be $i . i . d .\left(0, \sigma^{2} \mathbf{I}_{l}\right)$ and $|\rho|<1$. Given these assumptions, we can write:

$$
\varepsilon_{l}=\left(\mathbf{I}_{l}-\rho \mathbf{G}_{l}\right)^{-1} \boldsymbol{\xi}_{l}
$$

Performing a Cochrane-Orcutt-like transformation on the structural model in deviation, the latter is given by the following structural form:

$$
\mathbf{K}_{l} \mathbf{M}_{l} \mathbf{y}_{l}=\beta \mathbf{K}_{l} \mathbf{M}_{l} \mathbf{G}_{l} \mathbf{y}_{l}+\mathbf{K}_{l} \mathbf{M}_{l} \mathbf{X}_{l} \gamma+\mathbf{K}_{l} \mathbf{M}_{l} \mathbf{G}_{l} \mathbf{X}_{l} \boldsymbol{\delta}+\boldsymbol{\nu}_{l}
$$

where $\mathbf{X}_{l}$ is the matrix of adolescents' characteristics in the $l$ th network, $\mathbf{M}_{l}=\left(\mathbf{I}-\rho \mathbf{G}_{l}\right)$ and $\boldsymbol{\nu}_{l}=\mathbf{K}_{l} \boldsymbol{\xi}_{l}$.

The elimination of fixed network effects using a within transformation leads to a singular variance matrix such that $E\left(\boldsymbol{\nu}_{l} \boldsymbol{\nu}_{l}^{\prime} \mid \mathbf{X}_{l}, \mathbf{G}_{l}\right)=\mathbf{K}_{l} \mathbf{K}_{l}^{\prime} \sigma^{2}=\mathbf{K}_{l} \sigma^{2}$. To resolve this problem of linear dependency between observations, we follow a suggestion by Lee et al. (2010) and applied by Lin (2010). Let $\left[\begin{array}{ll}\mathbf{Q}_{l} & \left.\mathbf{C}_{l}\right]\end{array}\right.$ be the orthonormal matrix of $\mathbf{K}_{l}$, where $\mathbf{Q}_{l}$ corresponds to the eigenvalues of 1 and $\mathbf{C}_{l}$ to the eigenvalues of 0 . The matrix $\mathbf{Q}_{l}$ has the following properties: $\mathbf{Q}_{l}^{\prime} \mathbf{Q}_{l}=\mathbf{I}_{n_{l}^{*}}, \mathbf{Q}_{l} \mathbf{Q}_{l}^{\prime}=\mathbf{K}_{l}$ and $\mathbf{Q}_{l}^{\prime} \iota=0$, where $n_{l}^{*}=n_{l}-1$ with $n_{l}$ being the number of adolescents in the $l$ th network. Pre-multiplying (7) by $\mathbf{Q}_{l}^{\prime}$, the structural model can now be written as follows:

$$
\mathbf{M}_{l}^{*} \mathbf{y}_{l}^{*}=\beta \mathbf{M}_{l}^{*} \mathbf{G}_{l}^{*} \mathbf{y}_{l}^{*}+\mathbf{M}_{l}^{*} \mathbf{X}_{l}^{*} \gamma+\mathbf{M}_{l}^{*} \mathbf{G}_{l}^{*} \mathbf{X}_{l}^{*} \delta+\boldsymbol{\nu}_{l}^{*}
$$

where $\mathbf{M}_{l}^{*}=\mathbf{Q}_{l}^{\prime} \mathbf{M}_{l} \mathbf{Q}_{l}, \mathbf{y}_{l}^{*}=\mathbf{Q}_{l}^{\prime} \mathbf{y}_{l}, \mathbf{G}_{l}^{*}=\mathbf{Q}_{l}^{\prime} \mathbf{G}_{l} \mathbf{Q}_{l}, \mathbf{X}_{l}^{*}=\mathbf{Q}_{l}^{\prime} \mathbf{X}_{l}$, and $\boldsymbol{\nu}_{l}^{*}=\mathbf{Q}_{l}^{\prime} \boldsymbol{\xi}_{l}$. With this transformation, our problem of dependency between the observations is solved, since we have $E\left(\boldsymbol{\nu}_{l}^{*} \boldsymbol{\nu}_{l}^{* \prime} \mid \mathbf{X}_{l}, \mathbf{G}_{l}\right)=\sigma^{2} \mathbf{I}_{n_{l}^{*}}$.

Following Lee et al. (2010), we propose two approaches to estimate the peer effects model (8): a maximum likelihood approach (ML) and a generalized spatial two stage least squares (GS-2SLS) approach. The ML approach imposes more structure (normality) than GS-2SLS. Therefore, under some regularity 
conditions, ML estimators are more asymptotically efficient than GS-2SLS ones when the restrictions it imposes are valid.

\subsubsection{Maximum Likelihood (ML)}

Assuming that $\boldsymbol{\nu}_{l}^{*}$ is a $n_{l}^{*}$-dimensional normally distributed disturbance vector, the log-likelihood function is given by:

$$
\ln \mathbb{L}=\frac{-n^{*}}{2} \ln \left(2 \pi \sigma^{2}\right)+\sum_{l=1}^{L} \ln \left|\mathbf{I}_{n_{l}^{*}}-\beta \mathbf{G}_{l}^{*}\right|+\sum_{l=1}^{L} \ln \left|\mathbf{I}_{n_{l}^{*}}-\rho \mathbf{M}_{l}^{*}\right|-\frac{1}{2 \sigma^{2}} \sum_{l=1}^{L} \boldsymbol{\nu}_{l}^{* \prime} \boldsymbol{\nu}_{l}^{*},
$$

where $n^{*}=\sum_{l=1}^{L} n_{l}^{*}=N-L$, and, from (8), $\boldsymbol{\nu}_{l}^{*}=\mathbf{M}_{l}^{*}\left(\mathbf{y}_{l}^{*}-\beta \mathbf{G}_{l}^{*} \mathbf{y}_{l}^{*}-\mathbf{X}_{l}^{*} \gamma-\mathbf{G}_{l}^{*} \mathbf{X}_{l}^{*} \delta\right)$. Maximizing (9) with respect to $\left(\beta, \gamma^{\prime}, \boldsymbol{\delta}^{\prime}, \rho, \sigma\right)$ yields the maximum likelihood estimators of the model. ${ }^{16}$ Interestingly, the ML method is implemented after the elimination of the network fixed effects. Therefore, the estimators are not subject to the incidental parameters problem that may arise since the number of fixed effects increases with the the size of the networks sample.

\subsubsection{Generalized spatial two stage least squares (GS-2SLS)}

To estimate the model (8), we also adopt a generalized spatial two-stage least squares procedure presented in Lee et al. (2010). This approach provides a simple and tractable numerical method to obtain asymptotically efficient IV estimators within the class of IV estimators. In the case of our paper this method will consist of a two-step estimation. ${ }^{17}$ To simply the notation, Let $\mathbf{X}^{*}$ be a block-diagonal matrix with $\mathbf{X}^{*}$ on its diagonal, $\mathbf{G}^{*}$ be a block-diagonal matrix with $\mathbf{G}^{*}$ on its diagonal, and $\mathbf{y}^{*}$ the concatenated vector of the $y_{l}^{* \prime}$ s over all networks.

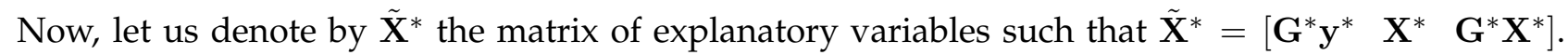

\footnotetext{
${ }^{16}$ For computational simplicity, one can concentrate the log-likelihood function (9) and maximize the concentrated loglikelihood function. See Lee et al. (2010) for more details.

${ }^{17}$ Note that for this particular case we impose $\rho=0$ and thus $M_{l}=I_{l}$.
} 
Let $\mathbf{P}$ be the weighting matrix such that $\mathbf{P}=\mathbf{S}\left(\mathbf{S}^{\prime} \mathbf{S}\right)^{-1} \mathbf{S}^{\prime}$, and $\mathbf{S}$ a matrix of instruments such that $\mathbf{S}=$ $\left[\begin{array}{lll}\mathbf{X}^{*} & \mathbf{G}^{*} \mathbf{X}^{*} \quad \mathbf{G}^{* 2} \mathbf{X}^{*}\end{array}\right]$. In the first step, we estimate the following 2SLS estimator:

$$
\hat{\boldsymbol{\theta}}_{1}=\left(\tilde{\mathbf{X}}^{* \prime} \mathbf{P} \tilde{\mathbf{X}}^{*}\right)^{-1} \tilde{\mathbf{X}}^{* \prime} \mathbf{P} \mathbf{y}^{*}
$$

where $\boldsymbol{\theta}$ is the vector of parameters $\left(\boldsymbol{\lambda}^{\prime}, \boldsymbol{\delta}^{\prime}, \beta\right)$ of the structural model.

In the second step we estimate a 2SLS using $\hat{\mathbf{Z}}$ as instruments. To avoid any confusion with the first step, let us denote this new matrix of instruments $\hat{\mathbf{Z}}$ such that $\hat{\mathbf{Z}}=\mathbf{Z}\left(\hat{\boldsymbol{\theta}}_{1}\right)$ with:

$$
\mathbf{Z}(\boldsymbol{\theta})=\left[\mathbf{E}\left[\mathbf{G}^{*} \mathbf{y}^{*}(\boldsymbol{\theta}) \mid \mathbf{X}^{*}, \mathbf{G}^{*}\right] \quad \mathbf{X}^{*} \quad \mathbf{G}^{*} \mathbf{X}^{*}\right]
$$

and where

$$
E\left[\mathbf{G}^{*} \mathbf{y}^{*}(\boldsymbol{\theta}) \mid \mathbf{X}^{*}, \mathbf{G}^{*}\right]=\mathbf{G}^{*}\left(\mathbf{I}-\beta \mathbf{G}^{*}\right)^{-1}\left[\left(\mathbf{X}^{*} \gamma+\mathbf{G}^{*} \mathbf{X}^{*} \delta\right)\right]
$$

We then estimate:

$$
\hat{\boldsymbol{\theta}}_{2}=\left(\hat{\mathbf{Z}}^{\prime} \tilde{\mathbf{X}}^{*}\right)^{-1} \hat{\mathbf{Z}} \mathbf{y}^{*}
$$

This estimator can be shown to be asymptotically best IV estimator. Its asymptotic variance matrix is given by $N\left[\mathbf{Z}^{\prime} \tilde{\mathbf{X}}^{*} \mathbf{R}^{-1} \tilde{\mathbf{X}}^{*} \mathbf{Z}\right]^{-1}$.

The matrix $\mathbf{R}$ is consistently estimated by

$$
\hat{\mathbf{R}}=s^{2} \frac{\hat{\mathbf{Z}}^{\prime} \hat{\mathbf{Z}}}{N}
$$

where $s^{2}=N^{-1} \sum_{i=1}^{N}{\hat{u_{i}}}^{2}$ and $\hat{u}_{i}$ are the residuals from the second step. It is important to note that, as in Kelejian and Prucha (1998), we assume that errors are homoscedastic. The estimation theory developed by Kelejian and Prucha (1998) under the assumption of homoscedastic errors does not apply if we assume heteroscedastic errors (Kelejian and Prucha, Forthcoming, 2010).

\subsection{A weight gain production function}

In this section, we propose a weight gain production function that relates an adolescent's BMI in time $t$ to his lagged BMI, his fast food consumption as well as his own characteristics in period $t$. Let $y_{i t}^{b}$ be an 
adolescent $i$ 's BMI level at time $t$, and $y_{i t}^{f}$ be the adolescent's fast food consumption. Then, for a given vector of characteristics $\tilde{\mathbf{x}}_{i t}$, the weight gain production function can be formally expressed as follows (for notational simplicity we suppress $l$ ):

$$
y_{i t}^{b}=\pi_{0}+\pi_{1} y_{i, t-1}^{b}+\pi_{2} y_{i t}^{f}+\pi_{3} \tilde{\mathbf{x}}_{i t}+\eta_{i t},
$$

where

$$
\eta_{i t}=\mu_{i}+\zeta_{i t}
$$

with $\mu_{i}$ representing the individual $i$ 's time-invariant error component (unobserved heterogeneity) and $\zeta_{i t}$, his idiosyncratic error that may change across $t$. We consider that $\mu_{i}$ is a fixed effect, $\left|\pi_{1}\right|<1$ and that the error $\zeta_{i t}$ is serially uncorrelated. As discussed earlier, our interest in this production function goes beyond a mere association between fast food consumption and weight gain. We are particularly interested to analyze the magnitude of a change in BMI resulting from a common exogenous shock on fast food consumption within the network, when peer effects are taken into account. Our two equation model allows us to compute this result. Partially differentiating (10) with respect to $y_{i t}^{f}$ and using the social multiplier $[=1 /(1-\beta)]$ yields the magnitude of a short run change in BMI (i.e., for $y_{i, t-1}^{b}$ given) resulting from a common marginal shock on fast food consumption: $\partial y_{i t}^{b} / \partial \alpha_{l}=\frac{\pi_{2}}{1-\beta}$. This expression entails two components: the impact of the fast food consumption on the BMI $\left(=\pi_{2}\right)$ and the multiplier effect $\left(=\frac{1}{1-\beta}\right)$.

At this point it is important to mention that OLS estimates of (10) will not be consistent for two reasons. First, the adolescent's fast food consumption is not exogenously determined and may be affected by his own BMI. In addition, there may exist a correlation between lagged dependent variable and the error term due to the presence of a time-invariant error component. One way to resolve this issue is to apply a first difference. While such a transformation wipes out all individual time-invariant characteristics, it has the advantage of making the correlation between right hand side regressors and the error term easier to handle. Formally, assuming that all characteristics (except age) are time-invariant, the 
transformed model can be written as follows:

$$
\Delta y_{i t}^{b}=\tilde{\pi_{0}}+\pi_{1} \Delta y_{i, t-1}^{b}+\pi_{2} \Delta y_{i t}^{f}+\Delta \zeta_{i t},
$$

where $\Delta$ is the first difference operator. To resolve the problem of correlation between the right hand side variables and the error term one can instrument for $\Delta y_{i, t-1}^{b}$ and $\Delta y_{i t}^{f}$. To instrument the lagged dependent variable we can either use $\Delta y_{i, t-2}^{b}$ or $y_{i, t-2}^{b}$ (Hsiao, 1981). Following the suggestion of Arellano and Bond (1991), we instrument it using $y_{t-2}^{b}$. We also use birthweight $x_{b w}$. As for the fast food

consumption variable $\Delta y_{i t}^{f}$, valid instruments could be $y_{i 1}^{f}, y_{i 2}^{f}, y_{i 3}^{f}, \ldots, y_{i, s-1}^{f}$ for an equation differenced at $t=s$. Unfortunately such information is not available in our dataset, we thus instrument it using the strictly exogenous variables that we have used in our peer effects model.

To estimate the model in (11), let us define $\Delta \mathbf{X}^{b}$ the matrix of explanatory variables such that $\Delta \mathbf{X}^{b}=$

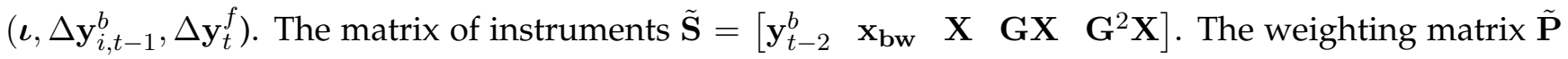
is defined such that $\tilde{\mathbf{P}}=\tilde{\mathbf{S}}\left(\tilde{\mathbf{S}}{ }^{\prime} \tilde{\mathbf{S}}\right)^{-1} \tilde{\mathbf{S}}^{\prime}$. For a vector of parameters $\tilde{\boldsymbol{\theta}}=\left(\pi_{0}, \pi_{1}, \pi_{2}\right)$, the estimates are given by :

$$
\hat{\tilde{\boldsymbol{\theta}}}=\left[\left(\Delta \mathbf{X}^{b}\right)^{\prime} \tilde{\mathbf{P}}\left(\Delta \mathbf{X}^{b}\right)\right]^{-1}\left(\Delta \mathbf{X}^{b}\right)^{\prime} \tilde{\mathbf{P}} \Delta \mathbf{y}^{b}
$$

\section{Data and Descriptive Statistics}

The Add Health survey is a longitudinal study that is nationally representative of American adolescents in grades 7 through 12. It is one of the most comprehensive health surveys that contains fairly exhaustive social, economic, psychological and physical well-being variables along with contextual data on the family, neighbourhood, community, school, friendships, peer groups, romantic relationships, etc. In the first wave (September 1994 to April 1995), all students (around 90 000) attending the randomly selected high schools were asked to answer a short questionnaire. An in-home sample (core sample) of approximately 20000 students was then randomly drawn from each school. These adolescents were asked to participate in a more extensive questionnaire where detailed questions were asked. Information on 
(but not limited to) health, nutrition, expectations, parents' health, parent-adolescent relationship and friends nomination was gathered. ${ }^{18}$ This cohort was then followed in-home in the subsequent waves in 1996 (wave II) and 2001 (wave III). The extensive questionnaire was also used to construct the saturation sample that focuses on 16 selected schools (about 3000 students). Every student attending these selected schools answered the detailed questionnaire. There are two large schools and 14 other small schools. All schools are racially mixed and are located in major metropolitan areas except one large school that has a high concentration of white adolescents and is located in a rural area. Consequently, fast food consumption may be subject to downward bias if one accepts the argument that the fast food consumption among white adolescents is usually lower than that of black adolescents. ${ }^{19}$

In this paper we use the saturation sample of wave II in-home survey to investigate the presence of peer effects in fast food consumption. ${ }^{20}$ One of the innovative aspects of this wave is the introduction of the nutrition section. It reports among other things food consumption variables (e.g., fast food, soft drinks, desserts, etc.). This allows us to depict food consumption patterns of each adolescent and relate it to that of his peer group. In addition, the availability of friend nomination allows us to retrace school friends and thus construct friendship networks. ${ }^{21}$ To estimate the weight gain production function, we considered information from wave I, wave II and wave III.

We exploit friends nominations to construct the network of friends. Thus, we consider all nominated friends as network members regardless of the reciprocity of the nomination. If an adolescent nominates a friend then a link is assigned between these two adolescents.

\footnotetext{
${ }^{18}$ Adolescents were asked to nominate either 1 female friend and 1 male friend or 5 female friends and 5 male friends.

${ }^{19}$ It is unclear whether the black population consumes more fast food than the white population. Block et al. (2004) provides evidence that predominantly black neighbourhoods have relatively more fast food restaurants than predominantly white neighbourhoods.

${ }^{20}$ It includes all meals that are consumed at a fast food restaurant such as McDonald's, Burger King, Pizza Hut, Tacco Bell.

${ }^{21}$ In the saturation sample, all students are asked to name their friends.
} 


\subsection{Descriptive statistics}

In our peer effects model, the dependent variable of interest is fast food consumption, as approximated by the reported frequency (in days) of fast food restaurant visits in the past 7days. Table 1 reports respectively the mean and the standard deviation of the endogenous variable, the covariates used and other relevant characteristics. We note that on average, adolescents' fast food consumption is fairly within the range of 2.33 times/week. This is consistent with the frequency reported by the Economic Research Service of the United States Department of Agriculture (Lin et al., 1996). Around 62\% of the adolescents consumed fast food twice or more in the past week and $44 \%$ of the adolescents who had consumed fast food did so 3 times in the past week. We also inspected the data to check for the presence of parental intervention in eating habits. We note that parents are absent $38 \%$ of the times during the consumption of evening meals and that $83 \%$ of children have the freedom to chose their meals. ${ }^{22}$ Evening meals are the only time parents have the power to check on the quality/quantity of the food consumed. This coupled with the freedom to choose food leaves the door wide open for peer influence in fast food consumption.

The covariates of the fast food peer effect equation include the adolescent's personal characteristics, family characteristics as well as the corresponding contextual social effects. The personal characteristics are gender, age, ethnicity (white or other) and grade. We observe that $50 \%$ of the sample are females, that the mean age is 16.3 years and that $57 \%$ are white. Family characteristics are dummies for mother and father education. We observe that around $45 \%$ of mothers and fathers have at least some college education. To control further for parents' income we use child allowance as a proxy. An adolescent's allowance is on average 8.28 per week, around 50\% of the adolescents in our the sample have a weekly allowance. At this point, it is important to highlight that since we use cross section data, we do not have to control for fast food prices as they are taken into account by network fixed effects. As for the weight gain production function, the dependent variable that we use is the variation in the BMI between waves two and three. The covariates are the fast food consumption, the lagged BMI (Table 2), age, and

\footnotetext{
${ }^{22}$ These figures are not reported in the paper but can be provided upon request.
} 
all time-invariant variables appearing in Table 1.

\subsection{The Construction of the Graph Matrix}

We construct a sub-matrix of graph for each school separately (matrice $\mathbf{G}_{l}$ ) and then we include all these sub-matrices in the block-diagonal matrix G. $^{23}$ As we have no prior information about how social interaction takes place, we assume, as in most studies, that an adolescent is equally influenced by his nominated friends. Further, we assume this influence decreases with the number of friends. In each school we eliminate adolescents for which we have missing values. We allow the sub-matrices to contain adolescents that are isolated. Since these latter may be friends with other adolescents in the network, they may affect the network even if they claim not to have any friends at all. They also introduce variability that helps the identification of the model. We also do not impose symmetry on the $\mathbf{G}$ matrix. In a more general sense we allow for a "Twitter" rather than "Facebook" type of networking. This imposes less restriction on the social interaction and mimics better the social interaction. Finally, the structural parameters of our peer effects model are identified, since $\mathbf{I}, \mathbf{G}, \mathbf{G}^{2}$ and $\mathbf{G}^{3}$ are linearly independent in our data. ${ }^{24}$

\section{Results}

\subsection{Baseline: $O L S$ peer effects estimates}

We first estimate a naive $O L S$ of the peer effects model where we regress the fast food consumption of an adolescent on the average fast food consumption of his peers, his individual characteristics as well as the average characteristics of his peers. We then apply a panel-like within transformation to account

\footnotetext{
${ }^{23}$ Following the previous literature and given the lack of information on this matter, we assume that there can be social interactions within each school but no interactions across schools.

${ }^{24}$ This should not come as a surprise as social interactions through networks are generetically identified. The only case when they are not identified, that is, $\mathbf{I}, \mathbf{G}, \mathbf{G}^{2}$ and $\mathbf{G}^{3}$ are linearly dependent, is when the population of individuals is partitioned in groups and there are less than three groups with different sizes (see Bramoullé et al., 2009). In a group, each individual interacts with all other individuals but does not interact with anybody outside his group.
} 
for correlated effects $\left(O L S_{w}\right)$. It is clear that the estimates of naive $O L S$ and $O L S_{w}$ are inconsistent. The former ignores both correlated effects and simultaneity problems while the latter ignores simultaneity problems. However, they are reported to provide a baseline for this study.

Estimation results reported in Table 3 show that there is a positive significant peer influence in fast food consumption. According to the naive $O L S$ estimates, an adolescent would increase his weekly frequency (in days) of fast food restaurant visits by 0.21 in response to an extra day of fast food restaurant visits by his friends. On average, this corresponds to an increase of $9 \%(=0.21 / 2.33) . O L S_{w}$ estimate is slightly lower $(=0.15$, or $6.6 \%)$. This reduction in the estimated effect may partly be explained by the fact that adolescents in the same reference group tend to choose a similar level of fast food consumption partly because they are alike or face a common environment. How can we compare these results to those obtained previously in the related literature? Although there are few studies that investigated the presence of peer effects in fast food consumption, a richer body of literature has investigated a tangent issue : obesity. In their paper Trogdon et al. (2008) show $O L S$ results for peer effects in obesity of 0.30 . Also, Renna et al. (2008) reports endogenous effects of 0.16 for $O L S$ estimates. This makes our $O L S$ estimates comparable to those obtained in the literature on obesity.

As for the individual characteristics they seem to be increasing in age, father education and weekly allowance. Turning our attention to the contextual peer effects, we notice that fast food consumption decreases with mean peers' mother's education and increases with mean peers' father's education. The former result indicates that friends' mother education negatively affects an adolescent's fast food consumption.

\subsection{ML and GS-2SLS peer effects estimates}

Next, we estimate our linear-in-means (or GSAR) model with school fixed effects and using ML. We then estimate the finer version of this model by imposing spatial autoregressive disturbances to the 
latter model (GSARAR model). Also, given that ML approach imposes normality on the error term, we relax this assumption and estimate the model using a distribution free approach : GS-2SLS.

Estimation results displayed in Table 4 show a positive and statistically significant endogenous effect of 0.13 (or 5.5\%) for the GSAR model. This effect is slightly smaller than the ones obtained in the previous section. However, when we impose more structure on the error term (GSARAR model), the endogenous peer effect remains statistically significant and increases to 0.37 , suggesting that an adolescent would increase his weekly frequency (in days) of fast food restaurant visits by 0.37 ( or $15.7 \%$ ) in response to an extra day per week of fast food restaurant visits by his friends. The social multiplier associated with an exogenous increase in an adolescent fast food consumption is $1.59(=1 /(1-0.37))$, which reflects a fairly strong endogenous peer effect. ${ }^{25}$ The increase in the endogenous effect coefficient as a result of a finer specification imposed on the error term is comparable to the one obtained by Lin (2010) in an empirical application of the GSARAR model on peer effects in academic achievement. Also, our estimated autocorrelation parameters are negative and significant. This may provide evidence that friendship might be for other purposes than having a common preference in the formation of friends for fast food consumption. ${ }^{26}$ As for the magnitude of the endogenous effects, it remains lower than ones obtained in the literature on peer effects in obesity. ${ }^{27}$ Trogdon et al. (2008) estimate for the endogenous effect is 0.52 using an instrumental approach.

When we relax the normality assumption, the endogenous effect resulting from GS-2SLS estimation reveals to be smaller than the one obtained by ML (0.11 instead of 0.13$)$. However, it is no longer significant. This does not come as a surprise, as less structure is not without a cost in precision. This makes the GSARAR specification preferable to others, at least as long as the normality assumption is an appropriate assumption. To sum up, we can say that results in general are consistent with the hypothesis that fast food consumption is linked to issues of identity and friends (Story et al., 2002).

\footnotetext{
${ }^{25}$ As suggested by Glaeser et al. (2003), large social multipliers tend to occur when the endogenous effect is 0.33 or more.

${ }^{26}$ Lin (2010) also obtains a negative estimated autocorrelation parameter when her model takes endogenous and contextual effects into account.

${ }^{27}$ One possible explanation is that we are estimating peer effects using one potential behavioural channel.
} 
As for individual effects, they follow fairly the baseline model. Fast food consumption is positively associated with age and father's education as well as positively associated with weekly allowance. ${ }^{28}$ Mother's education seems to have a negative but non significant impact on fast food consumption. It is important to note that while the general perception is that fast food is an inferior good, the empirical evidence suggests that there is a positive income elasticity (McCracken and Brandt, 1987; Jekanowski et al., 2001; Aguiar and Hurst, 2005). Thus, the positive relation between fast food consumption and allowance is therefore in line with the positive relation between income and fast food consumption.

Turning our attention to the contextual social effects, fast food consumption increases with mean peers' father's education and decreases with mean peers' mother's education. This suggests that adolescents are perhaps more influenced by their friends' mothers than their own.

\subsection{Weight gain production function estimates}

Estimation results presented in the earlier sections are consistent with the presence of peer effects in fast food consumption. Nevertheless, we still need to provide evidence of the presence of a relationship between fast food consumption and weight gain. In this section we report estimates of the weight gain production function presented earlier. As noted above, the variables we used to instrument the fast food consumption variable $\Delta y_{i t}^{f}$ are the instruments previously used in the fast food consumption model.

Results from the Arellano and Bond (1991) estimator are reported in Table 5. Note that since the model is estimated using a first differencing (fixed effects) approach, parameters associated with timeinvariant covariates are not identified and therefore do not appear in the table (the constant is an estimate of age parameter). In line with our expectations, results reveal a positive significant impact of a change in fast food consumption on the BMI level. An extra day of fast food restaurant visits per week increases weight by $0.36 \mathrm{BMI}$ points (or by $1.54 \%$ ) within a year.

\footnotetext{
${ }^{28}$ McLellan et al. (1999) found results pointing in a similar direction and suggest that limiting pocket money may be a good way to promote healthy adolescent behaviour.
} 
The presence of a causal link between fast food consumption and BMI does not come as a surprise since previous findings have been pointing in this direction (Levitsky et al., 2004; Niemeier et al., 2006; Rosenheck, 2008). Somewhat surprisingly, lagged BMI level has a negative effect on current BMI level $(=-0.727)$. This suggests that an exogenous shock on weight gain has a stronger effect on BMI in the short term than in the long term. This may partly be explained by the fact that given a past increase in his BMI an adolescent may be induced to adopt more healthy eating habits.

The validity of these results rely heavily on the validity of the instruments that are used. In order to test the validity of the instruments a Sargan test is computed. The test statistic reported in Table 5 indicates that we do not reject the joint null hypothesis that the instruments are valid and that the over-identification restrictions are satisfied.

Combining the impact of fast food on weight gain with the social multiplier, our results suggest that, within a network, an extra day of fast food restaurant visits per week lead to a BMI increase of 0.56

points $\left(\frac{0.36}{1-0.37}\right)$, or $2.4 \%$ on average, within a year. These results highlight the role of peer effects in fast food consumption as one of the transmission mechanisms through which weight gain is amplified.

\section{Conclusion}

This paper investigates whether peer effects in adolescent weight gain partly flow through the eating habits channel. We first attempt to study the the presence of significant endogenous peer effects in fast food consumption. New methods based on spatial econometric analysis are used to identify and estimate our model, under the assumption that individuals interact through a friendship social network. Our results indicate that an increase in his friends' mean fast food consumption induces an adolescent to increase his own fast food consumption. This peer effect amplifies through a social multiplier the impact of any exogenous shock on fast food consumption. Our estimated social multiplier is 1.59. 
We also estimate a dynamic weight gain production function which relates the adolescent's Body Mass Index to his fast food consumption. Results are in line with our expectations; they reveal a positive significant impact of a change in fast food consumption on the change in BMI. Specifically, a one-unit increase in the weekly frequency (in days) of fast food consumption produces an increase in BMI by $1.5 \%$ within a year. This effect reaches $2.4 \%$ when the social multiplier is taken into account. Coupled with the reduction in the relative price of fast food and the increasing availability of fast food restaurants over time, the social multiplier could exacerbate the prevalence of obesity in the years to come. Conversely, this multiplier may contribute to the decline of the spread of obesity and the decrease in health care costs, as long as it is exploited by policy makers through tax and subsidy reforms encouraging adequate eating habits among adolescents.

There are many possible extensions to this paper. From a policy perspective, it would be interesting to investigate the presence of peer effects in physical activity of adolescents. A recent study by Charness and Gneezy (2009) finds that there is room for intervention in peoples' decisions to perform physical exercise through financial incentives. It would be thus valuable to investigate whether there is a social multiplier that can be exploited to amplify these effects. Furthermore, in the same way, it would be interesting to study the presence of peer effects weight perceptions. So far, most of the peer effects work has focused mainly on outcomes (BMI). At the methodological level, a possible extension would be to relax the normality assumption and to assume a Poisson or a Negative Binomial distribution to account for the count nature of the consumption data at hand. As far as we know, no work has been carried out in this area. Finally, it would be most useful to develop a general approach that would allow same sex and opposite sex peer effects to be different for both males and females. 


\section{References}

Abu-Abid, S., Szold, A. and Klausner, J. (2002), 'Obesity and cancer.' , Journal of medicine 33(1-4), 73.

Aguiar, M. and Hurst, E. (2005), 'Consumption versus expenditure', Journal of Political Economy 113(5), 919-948.

Arellano, M. and Bond, S. (1991), 'Some tests of specification for panel data: Monte Carlo evidence and an application to employment equations', The Review of Economic Studies 58(2), 277-297.

Auld, M. and Powell, L. (2008), 'Economics of Food Energy Density and Adolescent Body Weight', Economica 15, 1468-0335.

Berentzen, T., Petersen, L., Schnohr, P. and Sørensen, T. (2008), 'Physical activity in leisure-time is not associated with 10-year changes in waist circumference', Scandinavian Journal of Medicine $\mathcal{E}$ Science in Sports 18(6), 719-727.

Bleich, S., Cutler, D., Murray, C. and Adams, A. (2008), 'Why is the developed world obese?', Annual Review of Public health 29, 273-295.

Block, J., Scribner, R. and DeSalvo, K. (2004), 'Fast food, race/ethnicity, and income A geographic analysis', American Journal of Preventive Medicine 27(3), 211-217.

Bowman, S., Gortmaker, S., Ebbeling, C., Pereira, M. and Ludwig, D. (2004), 'Effects of fast-food consumption on energy intake and diet quality among children in a national household survey', Pediatrics 113(1), 112-118.

Bramoullé, Y., Djebbari, H. and Fortin, B. (2009), 'Identification of peer effects through social networks', Journal of Econometrics 150(1), 41-55.

Brock, W. A. and Durlauf, S. N. (2001), Interactions-based models, in J. Heckman and E. Leamer, eds, 'Handbook of Econometrics', Vol. 5 of Handbook of Econometrics, Elsevier, chapter 54, pp. 3297-3380.

Calabr, P., Golia, E., Maddaloni, V., Malvezzi, M., Casillo, B., Marotta, C., Calabrò, R. and Golino, P. (2009), 'Adipose tissue-mediated inflammation: the missing link between obesity and cardiovascular disease?', Internal and Emergency Medicine 4(1), 25-34.

Calle, E. (2007), ‘Obesity and cancer’, British Medical Journal 335(7630), 1107-1108.

Caraher, M. and Cowburn, G. (2007), 'Taxing food: implications for public health nutrition', Public Health Nutrition 8(08), 1242-1249.

Charness, G. and Gneezy, U. (2009), 'Incentives to exercise', Econometrica 77(3), 909-931.

Chen, S. E., Florax, R. J. and Snyder, S. D. (2009), Obesity in urban food markets: Evidence from georeferenced micro data, 2009 Annual Meeting, July 26-28, 2009, Milwaukee, Wisconsin 49512, Agricultural and Applied Economics Association.

Chou, S.-Y., Rashad, I. and Grossman, M. (2005), Fast-food restaurant advertising on television and its influence on childhood obesity, NBER Working Papers 11879, National Bureau of Economic Research. 
Christakis, N. and Fowler, J. (2007), 'The spread of obesity in a large social network over 32 years', New England Journal of Medicine 357(4), 370-379.

Clark, A. and Loheac, Y. (2007), 'It Wasnt Me, It Was Them!', Journal of Health Economics 26, 763-784.

Cliff, A. and Ord, J. (1981), Spatial processes: models \& applications, Pion Ltd.

Cohen-Cole, E. and Fletcher, J. M. (2008), Is obesity contagious?: social networks vs. environmental factors in the obesity epidemic, Technical report.

Currie, J., DellaVigna, S., Moretti, E. and Pathania, V. (2009), The effect of fast food restaurants on obesity, NBER Working Papers 47830, National Bureau of Economic Research.

Cutler, D., Glaeser, E. and Sphapiro, J. (2003), 'Why have americans become more obese?', Journal of Economic Perspectives 17, 93-118.

Dunn, R. A. (2008), 'Obesity and the Availability of Fast-Food: An Instrumental Variables Approach', SSRN eLibrary .

Durlauf, S. N. (2004), Neighborhood effects, Vol. 4 of Handbook of Regional and Urban Economics, Elsevier.

Ford, E., Williamson, D. and Liu, S. (1997), ‘Weight change and diabetes incidence: findings from a national cohort of US adults', American Journal of Epidemiology 146(3), 214.

Fowler, J. and Christakis, N. (2008), 'Estimating Peer Effects on Health in Social Networks: A Response to Cohen-Cole and Fletcher; Trogdon, Nonnemaker, Pais', Journal of health economics 27(5), 1400.

Glaeser, E., Sacerdote, B. and Scheinkman, J. (2003), 'The social multiplier', Journal of the European Economic Association 1(2-3), 345-353.

Hsiao, C. (1981), 'Autoregressive modelling and money-income causality detection', Journal of Monetary Economics 7(1), 85-106.

Hu, F., Manson, J., Stampfer, M., Colditz, G., Liu, S., Solomon, C. and Willett, W. (2001), ‘Diet, lifestyle, and the risk of type 2 diabetes mellitus in women', New England Journal of Medicine 345(11), 790.

Jaccard, J., Blanton, H. and Dodge, T. (2005), 'Peer influences on risk behavior: an analysis of the effects of a close friend', Developmental Psychology 41(1), 135-147.

Jacobson, M. and Brownell, K. (2000), 'Small taxes on soft drinks and snack foods to promote health', American Journal of Public Health 90(6), 854-857.

Jeffery, R. and French, S. (1998), 'Epidemic obesity in the United States: are fast foods and television viewing contributing?', American Journal of Public Health 88(2), 277.

Jekanowski, M., Binkley, J. and Eales, J. (2001), 'Convenience, accessibility, and the demand for fast food', Journal of Agricultural and Resource Economics 26(1), 58-74.

Kelejian, H. and Prucha, I. (1998), 'A generalized spatial two-stage least squares procedure for estimating a spatial autoregressive model with autoregressive disturbances', The Journal of Real Estate Finance and Economics 17(1), 99-121.

Kelejian, H. and Prucha, I. (Forthcoming, 2010), 'Specification and estimation of spatial autoregressive models with autoregressive and heteroskedastic disturbances', Journal of Econometrics . 
Kim, D. and Kawachi, I. (2006), 'Food taxation and pricing strategies to thin out the obesity epidemic', American journal of preventive medicine 30(5), 430-437.

Lee, L. (2003), ‘Best spatial two-stage least squares estimators for a spatial autoregressive model with autoregressive disturbances', Econometric Reviews 22(4), 307-335.

Lee, L.-F., Liu, X. and Lin, X. (2010), 'Specification and estimation of social interaction models with networks structure', The Econometrics Journal 13(2), 143-176.

Levitsky, D., Halbmaier, C. and Mrdjenovic, G. (2004), 'The freshman weight gain: a model for the study of the epidemic of obesity', International Journal of Obesity 28(11), 1435-1442.

Li, C., Engstrom, G., Hedblad, B., Calling, S., Berglund, G. and Janzon, L. (2006), 'Sex differences in the relationships between BMI, WHR and incidence of cardiovascular disease: a population-based cohort study', International Journal of Obesity 30(12), 1775-1781.

Lin, B., Guthrie, J. and Blaylock, J. (1996), The Diets of America's Children: Influence of Dining Out, Household Characteristics, and Nutrition Knowledge, US Dept. of Agriculture, Economic Research Service.

Lin, X. (2010), 'Identifying Peer Effects in Student Academic Achievement by Spatial Autoregressive Models with Group Unobservables', Journal of Labor Economics 28(4), 825-860.

Maggio, C. and Pi-Sunyer, F. (2003), 'Obesity and type 2 diabetes', Endocrinology and metabolism clinics of North America 32(4), 805-822.

Manski, C. F. (1993), 'Identification of endogenous social effects: The reflection problem', Review of Economic Studies 60(3), 531-42.

Marshall, T. (2000), 'Exploring a fiscal food policy: the case of diet and ischaemic heart disease', BMJ: British Medical Journal 320(7230), 301.

McCracken, V. and Brandt, J. (1987), 'Household consumption of food-away-from-home: total expenditure and by type of food facility', American Journal of Agricultural Economics 69(2), 274-284.

McLellan, L., Rissel, C., Donnelly, N. and Bauman, A. (1999), 'Health behaviour and the school environment in New South Wales, Australia', Social Science E Medicine 49(5), 611-619.

Moffit, R. (2001), Policy Interventions, Low equilibria, and Social Interaction (Social Dynamics), MIT press.

Niemeier, H., Raynor, H., Lloyd-Richardson, E., Rogers, M. and Wing, R. (2006), 'Fast food consumption and breakfast skipping: predictors of weight gain from adolescence to adulthood in a nationally representative sample', Journal of Adolescent Health 39(6), 842-849.

Powell, L., Auld, M., Chaloupka, F., OMalley, P. and Johnston, L. (2007), 'Access to fast food and food prices: relationship with fruit and vegetable consumption and overweight among adolescents', Adv Health Econ Health Serv Res 17, 23-48.

Powell, L. and Bao, Y. (2009), 'Food Prices, Access to Food Outlets and Child Weight Outcomes: A Longitudinal Analysis', Economics and Human Biology 7, 64-72.

Renna, F., Grafova, I. B. and Thakur, N. (2008), 'The effect of friends on adolescent body weight', Economics and Human Biology 6(3), 377-387. 
Robinson, T., Borzekowski, D., Matheson, D. and Kraemer, H. (2007), 'Effects of fast food branding on young children's taste preferences', Archives of Pediatrics and Adolescent Medicine 161(8), 792.

Rogers, P., Fusinski, K., Rathod, M., Loiler, S., Pasarica, M., Shaw, M., Kilroy, G., Sutton, G., McAllister, E., Mashtalir, N. et al. (2007), 'Human adenovirus Ad-36 induces adipogenesis via its E4 orf-1 gene', International Journal of Obesity 32(3), 397-406.

Rolfes, S. and Whitney, E. (1996), 'Understanding nutrition', St. Paul: West Publishing Company .

Rosenheck, R. (2008), 'Fast food consumption and increased caloric intake: a systematic review of a trajectory towards weight gain and obesity risk', Obesity Reviews 9(6), 535-547.

Salvy, S.-J., Vartanian, L. R., Coelho, J. S., Jarrin, D. and Pliner, P. P. (2008), 'The role of familiarity on modeling of eating and food consumption in children', Appetite 50(2-3), $514-518$.

Stinebrickner, R. and Stinebrickner, T. R. (2006), 'What can be learned about peer effects using college roommates? evidence from new survey data and students from disadvantaged backgrounds', Journal of Public Economics 90, 1435-1454.

Story, M., Neumark-Sztainer, D. and French, S. (2002), 'Individual and environmental influences on adolescent eating behaviors', Journal of the American Dietetic Association 102(3S), 40-51.

Trogdon, J. G., Nonnemaker, J. and Pais, J. (2008), 'Peer effects in adolescent overweight', Journal of Health Economics 27(5), 1388-1399.

Yakusheva, O., Kapinos, K. and Weiss, M. (2010), 'Peer Effects and the Freshman 15: Evidence from a Natural Experiment', Mimeo . 
Table 1: Descriptive Statistics

\begin{tabular}{|c|c|c|}
\hline Variable & Mean & S.D \\
\hline Fast Food Consumption ${ }^{a}$ & 2.33 & 1.74 \\
\hline Female & .50 & .50 \\
\hline Age & 16.36 & 1.44 \\
\hline White & .57 & .49 \\
\hline Black & .15 & .34 \\
\hline Asian & .01 & .09 \\
\hline Native & .13 & .33 \\
\hline Other & .14 & .35 \\
\hline Mother Present & .85 & .35 \\
\hline Mother Education & & \\
\hline No high school degree & .15 & .35 \\
\hline High school/GED/Vocational Instead of high school & .36 & .48 \\
\hline Some College/Vocational After high school & .21 & .39 \\
\hline College & .18 & .38 \\
\hline Advanced Degree & .06 & .24 \\
\hline Don't Know & .04 & .20 \\
\hline Father Education & & \\
\hline No high school degree & .16 & .36 \\
\hline High school/GED/Vocational Instead of high school & .33 & .47 \\
\hline Some College/Vocational After high school & .17 & .37 \\
\hline College & .18 & .38 \\
\hline Advanced Degree & .08 & .26 \\
\hline Don't Know & .06 & .24 \\
\hline Missing & .02 & .16 \\
\hline Grade 7-8 & .11 & .32 \\
\hline Grade 9-10 & .27 & .44 \\
\hline Grade 11-12 & .62 & .48 \\
\hline Allowance per week & 8.28 & 11.65 \\
\hline Observations: & & 2355 \\
\hline
\end{tabular}

${ }^{a}$ Frequency (in days) of fast food restaurant visits in the past week. 
Table 2: Body Mass Index

\begin{tabular}{lrr} 
Variable & Mean & S.D \\
\hline \hline Bmi (wave1) & 22.81 & 4.59 \\
Bmi (wave2) & 23.24 & 4.76 \\
Bmi (wave3) & 26.78 & 6.31 \\
Birthweight & 7.40 & 1.38 \\
\hline \hline
\end{tabular}


Table 3: Peer effects in fast food consumption

\begin{tabular}{|c|c|c|c|c|c|c|}
\hline & \multicolumn{3}{|c|}{ OLS } & \multicolumn{3}{|c|}{ OLSw } \\
\hline & Coef. & & S.E & Coef. & & S.E \\
\hline Endogenous Peer Effects & 0.2078 & $* * *$ & 0.0331 & 0.1548 & $* * *$ & 0.0344 \\
\hline Individual Characteristics & & & & & & \\
\hline Female & -0.0721 & & 0.0787 & -0.0847 & & 0.0789 \\
\hline Age & 0.1559 & $* * *$ & 0.0434 & 0.1315 & $* * *$ & 0.0461 \\
\hline White & -0.1076 & & 0.0940 & -0.0602 & & 0.1127 \\
\hline Mother Present & -0.0152 & & 0.0997 & -0.0358 & & 0.0989 \\
\hline Mother No High School (Omitted) & & & & & & \\
\hline Mother High School & -0.0848 & & 0.1195 & -0.0455 & & 0.1202 \\
\hline Mother Some College & -0.0377 & & 0.1335 & -0.0210 & & 0.1340 \\
\hline Mother College & 0.0214 & & 0.1421 & -0.0137 & & 0.1425 \\
\hline Mother Advanced & -0.0259 & & 0.1875 & -0.0353 & & 0.1877 \\
\hline Mother Don't Know & -0.1714 & & 0.2067 & -0.2124 & & 0.2059 \\
\hline Father No High School (Omitted) & & & & & & \\
\hline Father High School & 0.2743 & $* *$ & 0.2067 & 0.2682 & ** & 0.1167 \\
\hline Father Some College & 0.2117 & & 0.2067 & 0.1971 & & 0.1338 \\
\hline Father College & 0.3115 & ** & 0.1375 & 0.2592 & * & 0.1381 \\
\hline Father Advanced & 0.1732 & & 0.1752 & 0.1294 & & 0.1760 \\
\hline Father Don't Know & 0.2778 & & 0.1756 & 0.2393 & & 0.1750 \\
\hline Father Missing & 0.0908 & & 0.2338 & 0.0477 & & 0.2331 \\
\hline Grade 7-8 (Omitted) & & & & & & \\
\hline Grade $9-10$ & 0.0883 & & 0.1931 & -0.0776 & & 0.2183 \\
\hline Grade $11-12$ & 0.3164 & & 0.2265 & 0.1269 & & 0.2526 \\
\hline Allowance per week & 0.0093 & $* * *$ & 0.0031 & 0.0074 & ** & 0.0031 \\
\hline
\end{tabular}

continued on next page 
Table 3: Continued

\begin{tabular}{|c|c|c|c|c|c|c|}
\hline & \multicolumn{3}{|c|}{ OLS } & \multicolumn{3}{|c|}{ OLSw } \\
\hline & Coef. & & S.E & Coef. & & S.E \\
\hline \multicolumn{7}{|l|}{ Contextual Peer Effects } \\
\hline Female & -0.0898 & & 0.1245 & -0.1071 & & 0.1285 \\
\hline Age & -0.0321 & & 0.0215 & 0.0316 & & 0.0718 \\
\hline White & 0.0111 & & 0.1244 & -0.0055 & & 0.1694 \\
\hline Mother Present & 0.0773 & & 0.1668 & 0.1008 & & 0.1707 \\
\hline \multicolumn{7}{|l|}{ Mother No High School (Omitted) } \\
\hline Mother High School & -0.3878 & ** & 0.1868 & -0.2977 & & 0.1913 \\
\hline Mother Some College & -0.3947 & * & 0.2127 & -0.3825 & * & 0.2168 \\
\hline Mother College & -0.2531 & & 0.2180 & -0.2935 & & 0.2213 \\
\hline Mother Advanced & -0.7011 & ** & 0.3089 & -0.5954 & * & 0.3112 \\
\hline Mother Don't Know & -0.4337 & & 0.3598 & -0.4150 & & 0.3610 \\
\hline \multicolumn{7}{|l|}{ Father No High School (Omitted) } \\
\hline Father High School & 0.2060 & & 0.1943 & 0.2999 & & 0.1914 \\
\hline Father Some College & 0.3639 & * & 0.2128 & 0.3890 & * & 0.2139 \\
\hline Father College & 0.2850 & & 0.2238 & 0.3068 & & 0.2263 \\
\hline Father Advanced & 0.2760 & & 0.2891 & 0.2171 & & 0.2953 \\
\hline Father Don't Know & 0.4737 & & 0.2995 & 0.5358 & * & 0.3001 \\
\hline Father Missing & 0.6931 & & 0.4619 & 0.7692 & * & 0.4640 \\
\hline \multicolumn{7}{|l|}{ Grade 7-8 (Omitted) } \\
\hline Grade 9-10 & -0.0769 & & 0.2383 & 0.0104 & & 0.2773 \\
\hline Grade 11-12 & -0.0094 & & 0.2630 & -0.0396 & & 0.3388 \\
\hline Allowance per week & 0.0056 & $* *$ & 0.0053 & 0.0043 & & 0.0054 \\
\hline Constant & -0.5199 & & 0.6618 & & & \\
\hline$N=2239$ & & & & & & \\
\hline
\end{tabular}




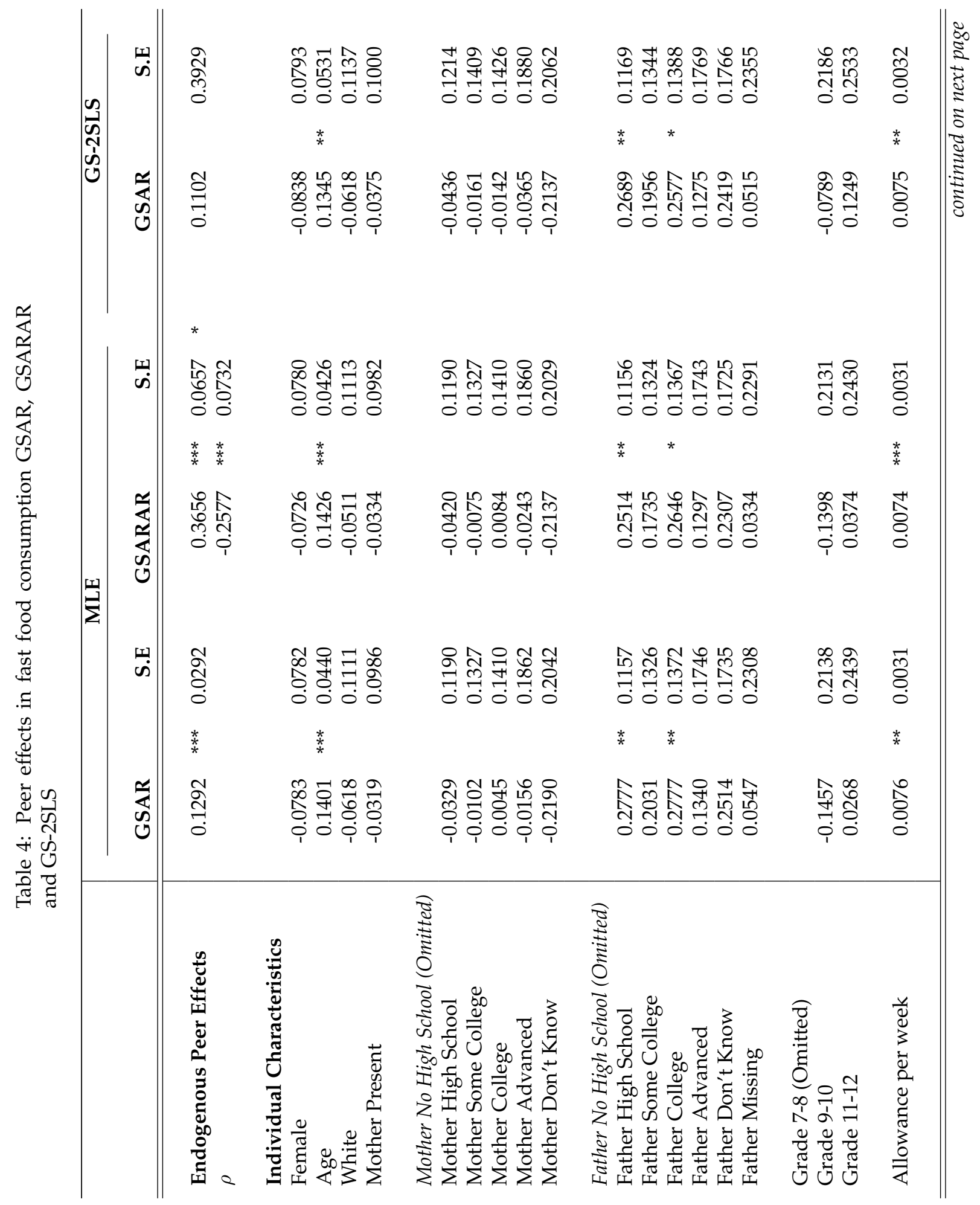




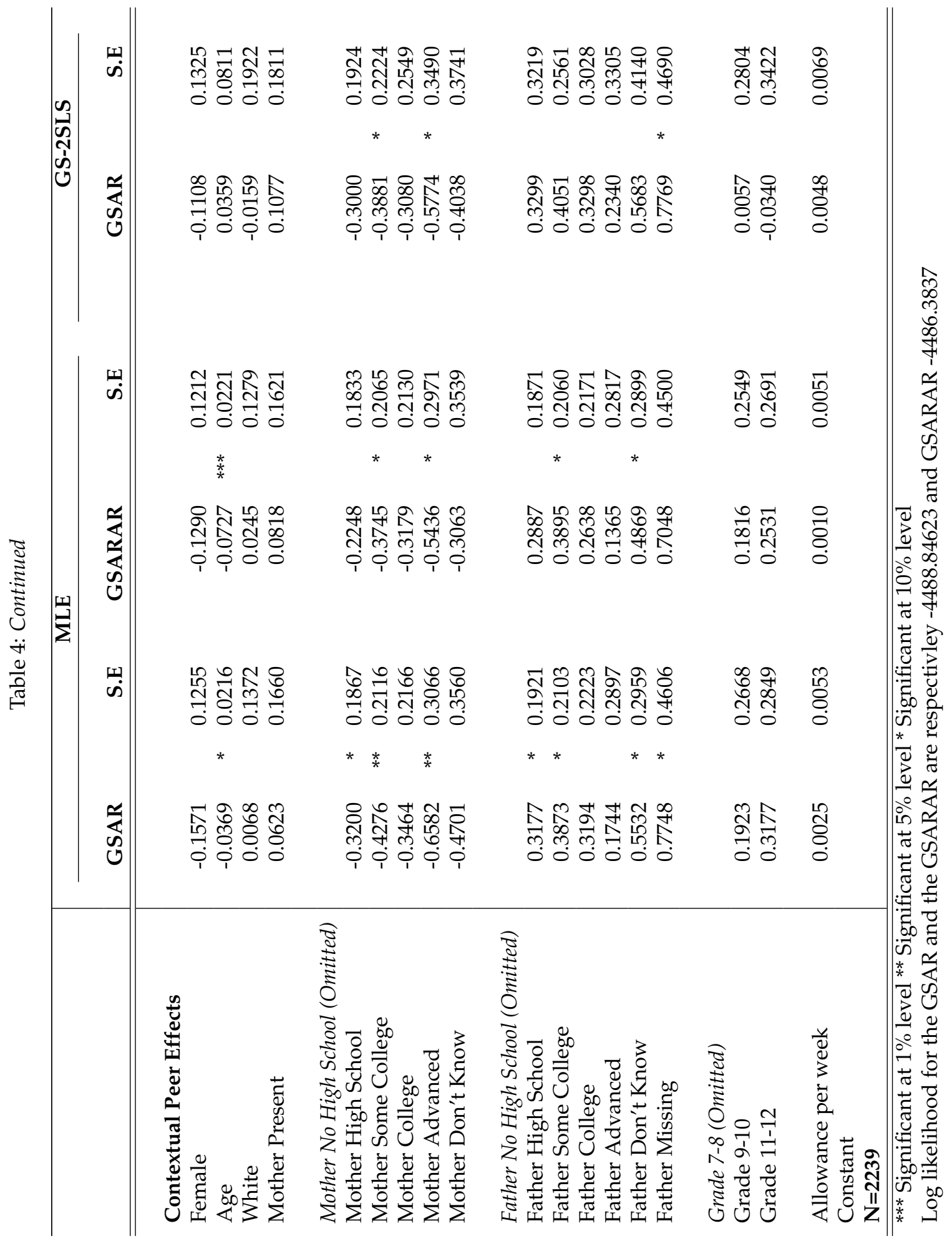


Table 5: Weight gain Production Function, Arellano and Bond

\begin{tabular}{lccl} 
& Coefficient & S.E & \\
\hline \hline Constant & 3.7206 & 0.13991 & $* * *$ \\
BMI $_{t-1}$ & -0.72737 & 0.19108 & $* * *$ \\
Fast food & $* .35761$ & 0.17936 & $* *$ \\
\hline & & & \\
Sargan test Chi2(57) & & 61.955 & \\
$\mathrm{~N}$ & & 1445 & \\
\hline \hline
\end{tabular}

